\title{
Comparison of Hemodynamic Changes Due to Endotracheal Intubation With Labetalol and Remifentanil in Severe Preeclamptic Patients Undergoing Cesarean Delivery With General Anesthesia
}

\author{
Susan Rasooli ${ }^{1}$, Farnaz Moslemi ${ }^{1}$, Reyhaneh Ari ${ }^{1}$, Hale Vazife Shenas ${ }^{1}$, Majid Shokoohi ${ }^{2}$
}

\begin{abstract}
Objectives: Stress replication to laryngoscopy and intubation are exaggerated in the patient with severe preeclampsia and this stress can lead to an increased risk of maternal mortality and morbidity. The aim of this study was to compare the efficacies of remifentanil and labetalol in attenuating these responses in women with violent preeclampsia undergoing cesarean section (C-section) with general anesthesia.

Materials and Methods: In this double-blind study, 70 women with violent preeclampsia undergoing cesarean delivery were randomly assigned to two groups to receive either remifentanil $1 \mu \mathrm{g} / \mathrm{kg}$ or labetalol $0.25 \mathrm{mg} / \mathrm{kg}$ before the induction of anesthesia. Then, blood pressure (BP) and heart rate (HR) were measured before and 1, 3, and 5 minutes after the intubation. The first and 5thminute Apgar scores were evaluated as well.

Results: All hemodynamic variables decreased in both groups after the administration of remifentanil or labetalol. Labetalol significantly attenuated the rise in BP and HR during laryngoscopy and intubation compared to remifentanil $(P<0.001)$. Eventually, no significant difference was found between the Apgar scores of the two groups ( $P=0.97$ and $P=0.19$, respectively).

Conclusion: Overall, the administration of labetalol before the inspiration of anesthesia can control stress replication to laryngoscopy and shows better intubation and more stability than remifentanil in patients with severe preeclampsia undergoing C-section.

Keywords: Labetalol, Remifentanil, Stress responses, Intubation, Preeclampsia
\end{abstract}

\section{Introduction}

Laryngoscopy and tracheal intubation are associated with exaggerated pressor responses in preeclamptic patients during the induction of anesthesia $(1,2)$. In addition, enhancement in pulmonary and systemic arterial pressures, as well as pulmonary capillary wedge pressure may cause transient but severe hypertension. This can lead to increased maternal intracranial pressure, cerebral hemorrhage, and cardiac failure with pulmonary edema and result in maternal morbidity and mortality $(3,4)$. Laryngoscopy and intubation induce catecholamine release and uteroplacental vasoconstriction and adversely affect the neonate well-being (5-7). Therefore, the precise control of stress replication is necessary during the inspiration of anesthesia in preeclamptic patients. Various pharmacologic attempts have so far been made to suppress these pressor responses like opioids, lidocaine, along with $\alpha$ and $\beta$ adrenergic blockers (8-14). Remifentanil is shown to attenuate hemodynamic replication to intubation. Further, it is ultra-short acting opioid and very metabolized by placenta esterase, thus the fetal to maternal ratio is low. It has a short onset and rapid recovery time as well (1,8-17). Similarly, labetalol is an $\alpha$ and $\left(\beta_{1} \&\right.$ $\beta_{2}$ ) adrenergic receptor blocker and competes with the other catecholamine for binding these sites, therefore, it can suppress increased blood pressure (BP) and heart rate owing to the activation of the sympathetic nervous system during the intubation $(9,16)$. The current study aimed to find whether the prophylactic administration of remifentanil or labetalol given before the induction of anesthesia can reduce maternal hemodynamic changes in response to laryngoscopy and endotracheal intubation in severe preeclamptic patients undergoing cesarean delivery with general anesthesia.

\section{Materials and Methods}

The present randomized, double-blind, and placebocontrolled clinical trial was conducted at Alzahra obstetrics and gynecology educational hospital, Tabriz, Iran. A prior computed sample size revealed that 32 subjects in each group would have an $80 \%$ power with $P<0.05$ to detect a $20 \%$ diversity in peak systolic arterial pressure (SAP). After the enactment of this research from the Ethical Committee of Tabriz University of

Received 6 July 2018, Accepted 3 December 2018, Available online 19 December 2018

${ }^{1}$ Department of Anesthesiology, Women's Reproductive Health Research Center, Alzahra Hospital, Tabriz University of Medical Sciences. ${ }^{2}$ Department of Anatomical Sciences, Faculty of Medicine, Tabriz University of Medical Sciences, Tabriz, Iran.

*Corresponding Author: Farnaz Moslemi, Tel:+989143111715, Email:moslemifa@gmail.com 
Medical Sciences, 70 preeclamptic parturients with ASA (The American Society of Anesthesiologists) physical status of II and III, aged 20-40 years, undergoing general anesthesia for cesarean section were randomly allocated to one of two groups receiving remifentanil $(1 \mu \mathrm{g} / \mathrm{kg}$ bolus $\mathrm{IV}, \mathrm{n}=35)$ or labetalol $(0.25 \mathrm{mg} / \mathrm{kg}$ bolus IV, $\mathrm{n}=35) 2$ or 5 minutes before the induction of anesthesia, respectively. Written and knowledgeable satisfaction was received from all patients as well.

Patients demonstrating ASA class IV or higher, respiratory diseases, and congestive heart failure, as well as those with complicated endotracheal intubation and the lack of patient consent for participation were excluded from the study.

All patients were preoxygenated by $6 \mathrm{~L} / \mathrm{min}$ flow of $100 \%$ oxygen for 3 minutes. Then, they were randomly assigned to receive remifentanil $1 \mu \mathrm{g} / \mathrm{kg}$ in group 1 $(\mathrm{n}=35)$ and labetalol $0.25 \mathrm{mg} / \mathrm{kg}$ in group $2(\mathrm{n}=35)$ 2 and 5 minutes before the induction of anesthesia, respectively. In addition, syringes for the medications were prepared and covered according to the random number list by an anaesthesia assistant who was blind to the study. Randomization was accomplished by a computer-created list of random numbers and BP and HRs were monitored with an automated cuff BP monitor. Patients' hemodynamic parameters were recorded by an anaesthesiologist who was unaware of the aim of the study.

The rapid sequence induction of anesthesia was performed with sodium thiopental $5 \mathrm{mg} / \mathrm{kg}$ and then succinylcholine $1.5 \mathrm{mg} / \mathrm{kg}$. Next, endotracheal tube (ETT) was performed and all patients were mechanically ventilated after cricoid pressure and 50 seconds following the latest injection. The maintenance of anesthesia was provided by isoflurane $1 \%$ and $50 \%$ N2o in oxygen. Patients' hemodynamic parameters including $\mathrm{HR}$, SAP, diastolic arterial pressure (DAP), and mean arterial pressure (MAP) were monitored and recorded immediately before ETT and 1, 3, and 5 minutes after the intubation. Apgar scores were evaluated for each neonate at the first and fiifth minutes after delivery.

Demographic data and other study variables were recorded and analyzed and the results were presented as mean \pm SD for parametric data. All data were analyzed by student's t-test and Mann-Whitney test was applied to measure the significance between the study groups. Furthermore, the chi-square and reiterated measure tests were used for qualitative data and the accuracy of qualitative data, respectively. Finally, the data were analyzed by SPSS software, version 17 and $P$ values $<0.05$ were considered statistically significant.

\section{Results}

From 75 cases, 5 patients were deprived because of technically difficult intubation $(n=2)$ and imperfect, unavailable or lost data for a perfect review $(n=3)$. The remaining 70 subjects were randomized in equal numbers of two groups and completed the study without protocol reversal.

Based on the results, there were no significant differences between the groups with respect to maternal age, weight, height, gestational age, and neonate's weight (Table 1).

Moreover, the baseline SAP (measured immediately before the intubation) did not significantly differ between the groups. Conversely, it decreased significantly after the induction of anesthesia using the repeated-measured tests for accurate evaluation. The magnitude of the decrease was greater in the labetalol group $(P<0.001)$ than the remifentanil group (Figure 1).

In addition, DAP, MAP, and heart rate variations decreased significantly after the administration of labetalol in response to tracheal intubation (Table 2).

Finally, none of the newborns required resuscitative measures in the first minute after birth and no significant difference was found between the Apgar scores in both groups $(P=0.97)$.

\section{Discussion}

Based on the findings of the present study the prophylactic administration of labetalol $0.25 \mathrm{mg} / \mathrm{kg} \mathrm{IV}$ resulted in significantly lower hemodynamic variations than remifentanil $1 \mu \mathrm{g} / \mathrm{kg}$ IV due to laryngoscopy and intubation in preeclamptic patients undergoing caesarean section (C-section), indicating the efficacy of labetalol in attenuating the stress responses. Additionally, the results revealed that the control of $\mathrm{BP}$ and $\mathrm{HR}$ remains for a more prolonged time with labetalol compared with remifentanil which is a short-acting agent and thus can better preserve the stability of maternal hemodynamic parameters, especially the HR.

According to different studies, stress reply during the inspiration of anesthesia and tracheal intubation may potentially enhance maternal mortality and morbidity and the fetal risks by enhancing the circulating catecholamine levels and decreasing the placental blood flow (1-4, $10,15,18)$. Therefore, it was assumed that intercepting the increment in the maternal catecholamine concentrations may improve placental blood flow and neonatal outcomes.

Most of the clinicians use adjuncts to attenuate the sympathetic response associated with laryngoscopy and intubation in high-risk patients. Different studies compared beta blockers with fentanyl, nitroprusside, nitroglycerine, and the like $(3-8,12,19)$.

For example, Yoo et al conducted a comparative doubleblind randomized study on 42 female subjects with severe preeclampsia undergoing $\mathrm{C}$-section and reported the efficacy of remifentanil $1 \mu \mathrm{g} / \mathrm{kg}$ in attenuating hemodynamic changes during tracheal intubation. However, its use was associated with maternal hypotension and neonate respiratory depression (20). In our study, the same dose of remifentanil was used and effective control of hemodynamic changes was observed without any adverse effect on neonatal well-being and Apgar score. 
Likewise, Ngan Kee et al, using remifentanil for the induction of anesthesia, investigated its maternal and neonatal effect and found that remifentanil can effectively attenuate hemodynamic responses during laryngoscopy and intubation, but may cause mild neonatal depression due to crossing the placenta (21).

A single bolus of $0.25 \mathrm{mg} / \mathrm{kg}$ labetalol effectively attenuates hemodynamic responses to laryngoscopy and tracheal intubation in parturients with severe preeclampsia and eclampsia undergoing delivery. Labetalol is an adrenergic receptor blocking agent with mild alpha 1 and predominant beta-adrenergic receptor blocking actions (alpha: beta blocked ratio of 1:7 for intravenous (IV) and 1:3 for per oral. administration). The onset of action of IV labetalol is 5 minutes (9).

In the present study, labetalol had a significantly better effect on hemodynamic responses than remifentanil and could control SAP, DAP, MAP, and HR more effectively

Table 1. Demographic Data

\begin{tabular}{lccc}
\hline & $\begin{array}{c}\text { Remifentanil } \\
(\mathbf{n}=\mathbf{3 5})\end{array}$ & $\begin{array}{c}\text { Labetalol } \\
(\mathbf{n}=35)\end{array}$ & $\boldsymbol{P}^{*}$ \\
\hline Age $(\mathrm{y})$ & $32.77 \pm 6.2$ & $33.49 \pm 6.6$ & 0.64 \\
Height $(\mathrm{cm})$ & $162.03 \pm 5.7$ & $162.51 \pm 5.2$ & 0.15 \\
Weight $(\mathrm{kg})$ & $80.74 \pm 9.01$ & $83.51 \pm 7.00$ & 0.71 \\
Gestational age (wk) & $34.23 \pm 3.8$ & $34.69 \pm 4.2$ & 0.57 \\
$\begin{array}{l}\text { Induction to delivery interval } \\
\text { (min) }\end{array}$ & $9.2 \pm 2.6$ & $8.51 \pm 2.7$ & 0.28 \\
\hline
\end{tabular}

Note: Data are mean $\pm S D ;{ }^{*} P<0.05$ is significant between the groups.

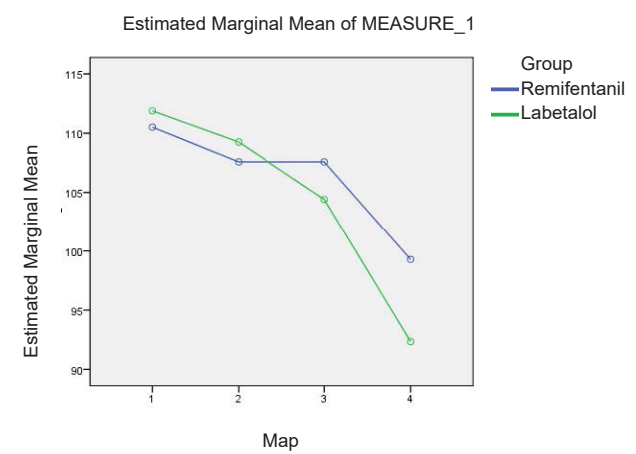

Estimated Marginal Mean of MEASURE_1

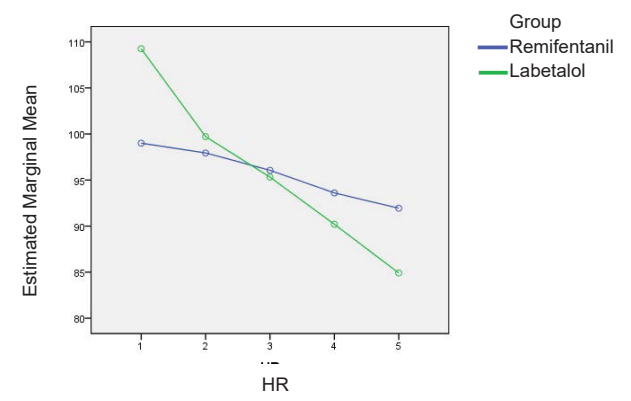

Figure 1. Hemodynamic (Mean Arterial Pressure and Heart Rate) Changes During Times in Two Groups.

compared to remifentanil with no adverse effect on neonatal well-being.

In another study, Ramanathan et al utilized labetalol for attenuating the hemodynamic response to endotracheal intubation in 25 preeclampsia parturients. In their study, patients with preeclampsia were randomly assigned to

Table 2. Hemodynamic Changes During Laryngoscopy and Intubation

\begin{tabular}{|c|c|c|c|}
\hline & Remifentanil ( $n=35)$ & Labetalol $(n=35)$ & $P$ Value ${ }^{*}$ \\
\hline \multicolumn{4}{|c|}{ Before laryngoscopy (baseline) } \\
\hline Systolic (mm Hg) & $145.54 \pm 10.8$ & $141.06 \pm 12.05$ & 0.16 \\
\hline Diastolic (mm Hg) & $96.6 \pm 11.18$ & $96.6 \pm 11.18$ & 0.58 \\
\hline Mean (mm Hg) & $110.5 \pm 13.10$ & $110.5 \pm 13.10$ & 0.06 \\
\hline Heart rate (beat/min) & $97.94 \pm 15.2$ & $99.7 \pm 10.5$ & 0.32 \\
\hline \multicolumn{4}{|c|}{ One min after intubation (mm Hg) } \\
\hline Systolic (mm Hg) & $137.37 \pm 12.5$ & $134.40 \pm 16.42$ & $<0.001$ \\
\hline Diastolic (mm Hg) & $98.5 \pm 12.8$ & $85.71 \pm 16.05$ & 0.34 \\
\hline Mean (mm Hg) & $107.57 \pm 10.5$ & $104.4 \pm 16.33$ & 0.54 \\
\hline Heart rate (beat/min) & $96.06 \pm 14.28$ & $95.31 \pm 9.7$ & 0.72 \\
\hline \multicolumn{4}{|c|}{ Three min after intubation ( $\mathrm{mm} \mathrm{Hg}$ ) } \\
\hline Systolic (mm Hg) & $137.00 \pm 12.7$ & $134.40 \pm 16.42$ & $<0.001$ \\
\hline Diastolic (mm Hg) & $88.26 \pm 14.7$ & $85.71 \pm 16.05$ & 0.17 \\
\hline Mean (mm Hg) & $107.5 \pm 16.9$ & $104.4 \pm 16.33$ & $<0.001$ \\
\hline Heart rate (beat/min) & $93.6 \pm 16.8$ & $90.2 \pm 12.03$ & $<0.001$ \\
\hline \multicolumn{4}{|c|}{ Five min after intubation ( $\mathrm{mm} \mathrm{Hg}$ ) } \\
\hline Systolic (mm Hg) & $132.23 \pm 11.90$ & $122.94 \pm 12.9$ & $<0.001$ \\
\hline Diastolic (mm Hg) & $75.3 \pm 13.7$ & $83.49 \pm 14.8$ & $<0.001$ \\
\hline Mean (mm Hg) & $92.3 \pm 12.9$ & $80.2 \pm 12.03$ & $<0.001$ \\
\hline Heart rate (beat/min) & $91.9 \pm 11.6$ & $84.9 \pm 11.06$ & $<0.001$ \\
\hline
\end{tabular}

Note: Data are mean \pm SD; $* P<0.05$ is significant between the groups. 
receive either labetalol (total dose of $1 \mathrm{mg} / \mathrm{kg}$ ) or placebo. They found that the hemodynamic responses were blinded during tracheal intubation (22).

In contrast, Inada et al applied $0.14 \mathrm{mg} / \mathrm{kg}$ labetalol and concluded that it was ineffective in attenuating the rise in systolic pressure. This difference might be related to the use of a lower dose and probably the timing of the labetalol administration of this low dose (2 minutes prior to intubation) in which the peak effect of the drug was lost at intubation (23).

Singh et al also compared the efficacy of esmolol and labetalol in low doses for the attenuation of the sympathomimetic response to laryngoscopy and intubation. Patients were allocated to three groups of 25 cases and were administered labetalol $0.25 \mathrm{mg} / \mathrm{kg}$, esmolol $0.5 \mathrm{mg} / \mathrm{kg}$ or normal saline as a placebo. The labetalol significantly attenuated the rise in HR and systolic BP during laryngoscopy and intubation compared to placebo and esmolol. However, the difference was not significant among the values for DBP and MAP (24). Therefore, it appears that the dose and timing of giving the labetalol prior to intubation are important for its effectiveness.

\section{Conclusions}

In patients with severe preeclampsia undergoing a cesarean section, labetalol $(0.25 \mathrm{mg} / \mathrm{kg})$ is considered as a better agent for attenuating the sympathomimetic response to laryngoscopy and intubation before the induction of anesthesia when compared to remifentanil.

\section{Conflict of Interests}

Authors declare that they have no conflict of interests.

\section{Ethical Issues}

The study was approved by the Institutional Committee of Ethics at Tabriz University of Medical Science (No. 9353) and was registered in the Iranian Registry of Clinical Trials (identifier: IRCT2014022810765N5).

\section{Financial Support}

None.

\section{References}

1. Hodgkinson R, Husain FJ, Hayashi RH. Systemic and pulmonary blood pressure during caesarean section in parturients with gestational hypertension. Can Anaesth Soc J. 1980;27(4):389-394. doi:10.1007/bf03007461

2. Kimura A, Yamakage M, Chen X, Kamada Y, Namiki A. Use of the fibreoptic stylet scope (Styletscope) reduces the hemodynamic response to intubation in normotensive and hypertensive patients. Can J Anaesth. 2001;48(9):919-923. doi:10.1007/bf03017360

3. Dyer RA, Piercy JL, Reed AR. The role of the anaesthetist in the management of the pre-eclamptic patient. Curr Opin Anaesthesiol. 2007;20(3):168-174. doi:10.1097/ ACO.0b013e328136clac

4. Polley LS. Hypertensive disorders. In: Chestnut DH,
Polley LS, Tsen LC, Wong CA, eds. Chestnut's Obstetric anaesthesia: Principles and practice. 4th ed. Philadelphia: Mosby Elsevier; 2009. p. 975-1003.

5. Gin T, O'Meara ME, Kan AF, Leung RK, Tan P, Yau G. Plasma catecholamines and neonatal condition after induction of anaesthesia with propofol or thiopentone at caesarean section. Br J Anaesth. 1993;70(3):311-316. doi:10.1093/bja/70.3.311

6. Lawes EG, Downing JW, Duncan PW, Bland B, Lavies N, Gane GA. Fentanyl-droperidol supplementation of rapid sequence induction in the presence of severe pregnancyinduced and pregnancy-aggravated hypertension. Br J Anaesth. 1987;59(11):1381-1391. doi:10.1093/ bja/59.11.1381

7. Park BY, Jeong CW, Jang EA, et al. Dose-related attenuation of cardiovascular responses to tracheal intubation by intravenous remifentanil bolus in severe pre-eclamptic patients undergoing Caesarean delivery. $\mathrm{Br} \mathrm{J}$ Anaesth. 2011;106(1):82-87. doi:10.1093/bja/aeq275

8. Hassani V, Movassaghi G, Goodarzi V, Safari S. Comparison of fentanyl and fentanyl plus lidocaine on attenuation of hemodynamic responses to tracheal intubation in controlled hypertensive patients undergoing general anesthesia. Anesth Pain Med. 2013;2(3):115-118. doi:10.5812/aapm.6442

9. MacCarthy EP, Bloomfield SS. Labetalol: a review of its pharmacology, pharmacokinetics, clinical uses and adverse effects. Pharmacotherapy. 1983;3(4):193-219. doi:10.1002/j.1875-9114.1983.tb03252.x

10. Servin F, Billard V. Remifentanil and other opioids. In: Schüttler J, Schwilden H, eds. Modern Anesthetics. Heidelberg: Springer; 2008. p. 283-311.

11. Ramanathan J, Coleman P, Sibai B. Anesthetic modification of hemodynamic and neuroendocrine stress responses to cesarean delivery in women with severe preeclampsia. Anesth Analg. 1991;73(6):772-779. doi:10.1213/00000539199112000-00016

12. Lee JH, Kim H, Kim HT, et al. Comparison of dexmedetomidine and remifentanil for attenuation of hemodynamic responses to laryngoscopy and tracheal intubation. Korean J Anesthesiol. 2012;63(2):124-129. doi:10.4097/kjae.2012.63.2.124

13. Loughran PG, Moore J, Dundee JW. Maternal stress response associated with caesarean delivery under general and epidural anaesthesia. Br J Obstet Gynaecol. 1986;93(9):943949. doi:10.1111/j.1471-0528.1986.tb08013.x

14. Noskova P, Blaha J, Bakhouche $\mathrm{H}$, et al. Neonatal effect of remifentanil in general anaesthesia for caesarean section: a randomized trial. BMC Anesthesiol. 2015;15:38. doi:10.1186/s12871-015-0020-1

15. Goyagi T, Yoshimoto M. Comparison of Hemodynamic Responses Associated with Tracheal Intubation Under Various Induction Doses of Remifentanil and Propofol. Open J Anesthesiol. 2012;2(4):154-160. doi:10.4236/ ojanes.2012.24035

16. Kitamura T, Yamada Y, Chinzei M, Du HL, Hanaoka $\mathrm{K}$. Attenuation of haemodynamic responses to tracheal intubation by the styletscope. Br J Anaesth. 2001;86(2):275277. doi:10.1093/bja/86.2.275

17. Kumar R, Gandhi R, Mallick I, Wadhwa R, Adlakha N, Bose $\mathrm{M}$. Attenuation of hemodynamic response to laryngoscopy 
and endotracheal intubation with two different doses of labetalol in hypertensive patients. Egypt J Anaesth. 2016;32(3):339-344. doi:10.1016/j.egja.2016.04.004

18. Kan RE, Hughes SC, Rosen MA, Kessin C, Preston PG, Lobo EP. Intravenous remifentanil: placental transfer, maternal and neonatal effects. Anesthesiology. 1998;88(6):14671474. doi:10.1097/00000542-199806000-00008.

19. Draisci G, Valente A, Suppa E, et al. Remifentanil for cesarean section under general anesthesia: effects on maternal stress hormone secretion and neonatal well-being: a randomized trial. Int J Obstet Anesth. 2008;17(2):130136. doi:10.1016/j.ijoa.2008.01.002

20. Yoo KY, Jeong CW, Park BY, et al. Effects of remifentanil on cardiovascular and bispectral index responses to endotracheal intubation in severe pre-eclamptic patients undergoing Caesarean delivery under general anaesthesia. Br J Anaesth. 2009;102(6):812-819. doi:10.1093/bja/aep099

21. Ngan Kee WD, Khaw KS, Ma KC, Wong AS, Lee BB, $\mathrm{Ng}$ FF. Maternal and neonatal effects of remifentanil at induction of general anesthesia for cesarean delivery: a randomized, double-blind, controlled trial. Anesthesiology. 2006;104(1):14-20. doi:10.1097/00000542-20060100000004

22. Ramanathan J, Sibai BM, Mabie WC, Chauhan D, Ruiz AG. The use of labetalol for attenuation of the hypertensive response to endotracheal intubation in preeclampsia. Am J Obstet Gynecol. 1988;159(3):650-654. doi:10.1016/s00029378(88)80027-9

23. Inada E, Cullen DJ, Nemeskal AR, Teplick R. Effect of labetalol or lidocaine on the hemodynamic response to intubation: a controlled randomized double-blind study. J Clin Anesth. 1989;1(3):207-213. doi:10.1016/09528180(89)90043-3.

24. Singh SP, Quadir A, Malhotra P. Comparison of esmolol and labetalol, in low doses, for attenuation of sympathomimetic response to laryngoscopy and intubation. Saudi J Anaesth. 2010;4(3):163-168. doi:10.4103/1658-354x.71573

(c) 2019 The Author (s); This is an open-access article distributed under the terms of the Creative Commons Attribution License (http://creativecommons.org/licenses/by/4.0), which permits unrestricted use, distribution, and reproduction in any medium, provided the original work is properly cited. 